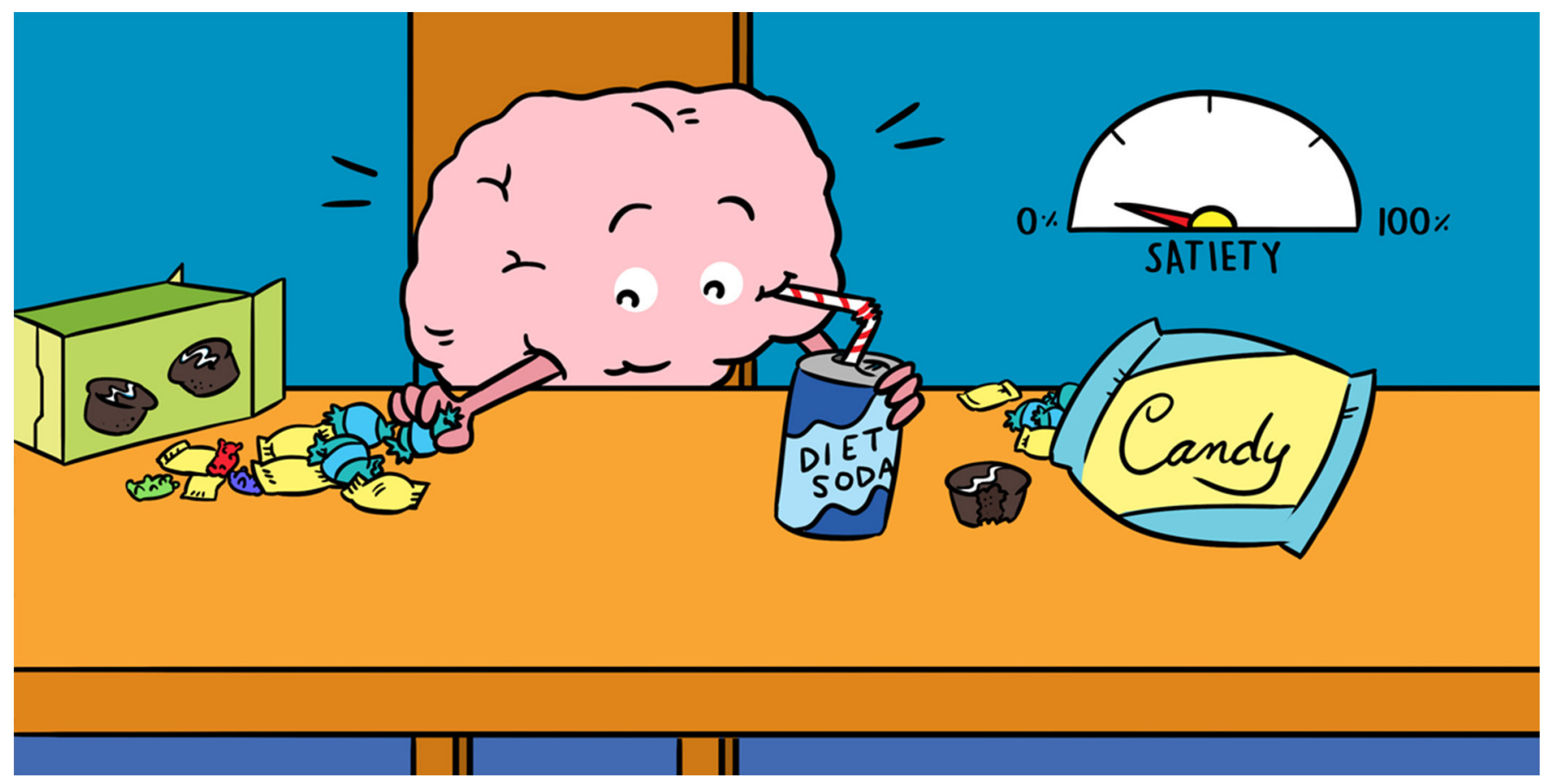

\title{
TRICK OR TREAT? HOW ARTIFICIAL SWEETENERS AFFECT THE BRAIN AND BODY
}

\section{Hunter Myüz and Michael C. Hout*}

\section{Department of Psychology, New Mexico State University, Las Cruces, NM, United States}

YOUNG REVIEWER:

VICTORIA
Why do sweet things taste so good? Sugar provides our bodies with energy (in the form of calories), which is probably why we have evolved to find it so delicious. Although we need calories, too many can make us gain weight, which can cause weight-related illnesses, like type 2 diabetes, and high blood pressure. Artificial sweeteners were invented to taste like sugar but have almost no calories; the goal was to have a sweetener that we could eat more of without developing diseases or gaining too much weight. However, artificial sweeteners sometimes have negative effects on the body and brain that sugars do not. Our brains, stomach microbes, and pancreases process artificial and real sugars differently-which can cause us to eat more, gain more weight, and have a harder time digesting the real sugars that our bodies need. Artificial sweeteners should be consumed in moderation, because they "trick" our brains and bodies into thinking they are treats-which can sometimes have negative health consequences. 


\section{ARTIFICIAL}

\section{SWEETENER}

A substitute for sugar that tastes sweet, but has few or zero calories. These are made by chemically altering existing sugars or amino acids.

\section{GLUCOSE}

A simple sugar that is an important energy source, and is naturally occurring in many foods.

\section{Figure 1}

One neuron communicating with another neuron; highlighted are the parts involved in "reward" transfer. The numbered dots indicate steps involved in this process.

Step 1: neurotransmitters are received from a previous neuron at receptor sites (that is, small machine-like parts of the cell that sense electricity and lead to the release of neurotransmitters), resulting in the firing of an action potential (that is, an electrical signal) by the cell body. Step 2: this electrical message travels down the axon of the neuron to the axon terminals.

Step 3: the neuron releases neurotransmitters into the space between this neuron and the one next to it. Step 4: the neurotransmitter crosses the space and is received by the next neuron, starting the process again.

\section{WHY DO SWEET THINGS TASTE SO GOOD?}

To understand why we like artificial sweeteners, we must first understand what makes us like real sugar. Sugar provides energy to our bodies in the form of calories, so we, like most other creatures, have evolved to enjoy it. Sugar comes in a variety of forms, such as glucose, sucrose, and fructose, but there are many more. Sugar increases activity in certain parts of our brains, which means that those parts become excited due to the incoming nutrition. Brain activation happens because of electrical activity that occurs within cells called neurons. All brain activity occurs in the form of electricity that is sent down small "wires" or "tunnels" in the neurons called axons. The electrical signal through the axons then results in the release of brain chemicals called neurotransmitters (see Figure 1). The "messages" that we get from the brain are communicated in the form of these neurotransmitters. Neurotransmitters set off reactions that lead to many different sensations that we feel-one of which is hunger.

Scientists have conducted studies involving both humans and other animals, and have discovered evidence that our need for energy is what drives our love of sweets. Although animals and humans can certainly be very different, many important discoveries have been made using animals in experiments that would be unfair, unsafe, or very difficult to perform on human participants. For instance, in one experiment, a group of rats was given food that was sweetened with glucose (a type of sugar), and a different group of rats was given food sweetened with artificial sweeteners. Then, both groups of rats were temporarily deprived of food, to make them hungry. After hunger was induced through food deprivation, the researchers found that when both groups of rats were given access to new glucose-sweetened food, the rats that were initially given artificially-sweetened food ate significantly more

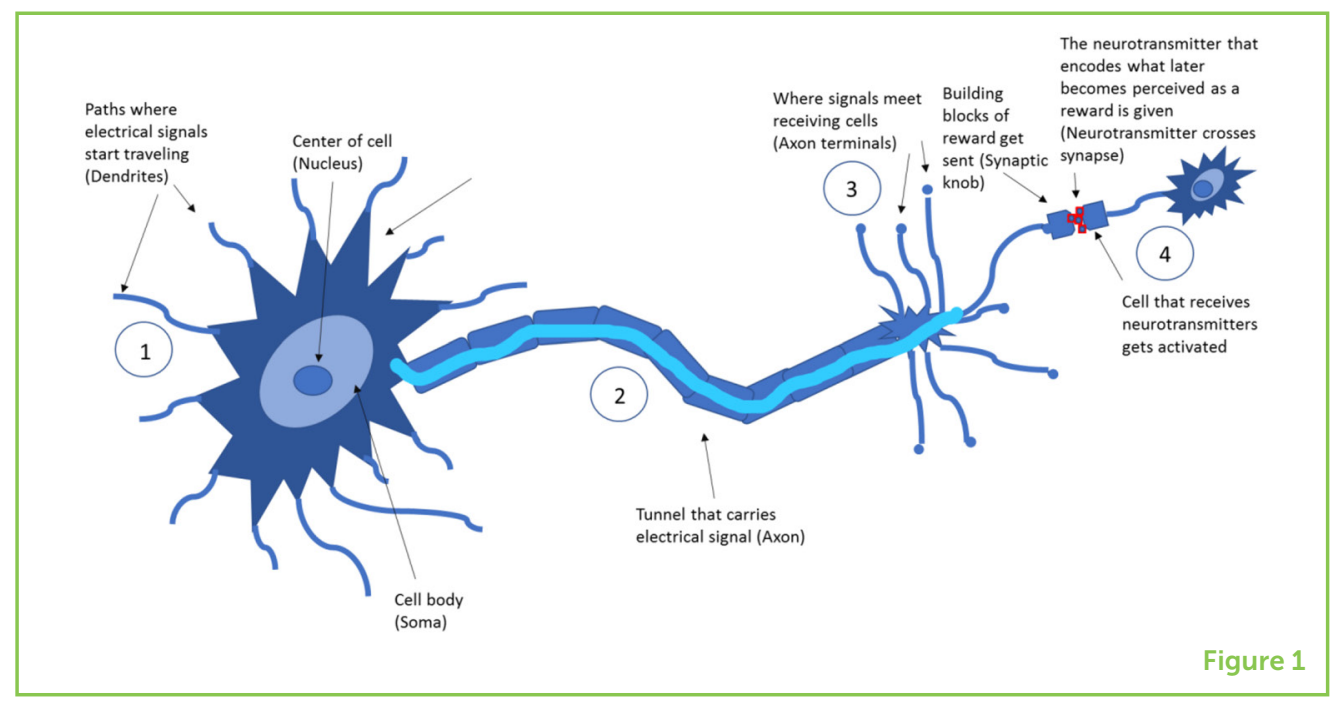




\section{NEURON}

A nerve cell that sends and receives electrical and chemical signals.

\section{NEUROTRANSMITTER}

A chemical substance released by neurons in the brain that send messages to our bodies and muscles. than those who were originally given glucose-sweetened food [1]. They over-ate the glucose-sweetened food because they had not been used to the connection between the sweet taste and its caloric content, due to having been given low-calorie, artificially-sweetened food initially. In effect, they were unable to make the connection between sweetness and nourishment.

In humans, our need for calories affects the way our brains work, too. Different parts of our brains get excited by sugar when we are hungry vs. when we are not. We know this from studies that changed people's hunger levels, by either providing study participants with food or not [2]. Unfortunately, our love of sweets can be bad for us when we are not in survival situations (which, thankfully, is most of our lives!), and can sometimes cause us to eat more than we need to. The more sugar, or sucrose, that we eat, the more we start to crave it. This is especially true when we are children, because as kids, we need lots of calories to grow big and strong. Some people's brains get more excited than average by looking forward to eating, which can lead to overeating. It is perhaps this tendency for eating too much that led to the invention of low- and zero-calorie sweeteners, such as saccharin, sucralose, aspartame, and acesulfame potassium. Although artificial sweeteners have fewer calories, which can help us lose weight and lower our blood sugar in the short-term, there are other health problems that these artificial sugars cause that may reverse these beneficial effects in the long-term.

Can you think of things that you eat or drink that have artificial sugars? We live in a world where many products are sweetened with artificial sugars, such as sports and energy drinks, sodas, chewing gum, some baked goods, and even ketchup! If we are going to keep consuming these artificial sweeteners, it is important to know how our brains and bodies are affected by them.

\section{BRAIN REACTIONS TO REAL VS. ARTIFICIAL SUGARS}

Although sometimes we cannot taste the difference between artificial and real sugars (despite the fact that they are actually very different), our brains and bodies can react to the differences. Our bodies can sometimes even detect very small differences between types of sugars and respond differently to each. Artificial sweeteners are highly concentrated-meaning that for the same physical amount, they can be between 200 to 13,000 times sweeter than sugar! Even though artificial sugars are sweeter than real ones, they are nearly caloriefree. In some studies, scientists have even found that people prefer the taste of artificial sugars over real ones. However, there is also data to 


\section{REWARD PATHWAY}

A series of connections in the brain that deliver neurotransmitters (such as dopamine) that make us feel good. suggest that there is greater brain activation in response to real sugar than to saccharin (a common artificial sugar), and this effect is particularly strong when people are hungry [2].

Our brains and bodies have different responses to artificial sweeteners and sugars because these substances are different from one another at the level of microscopic molecules. Reward pathways are like racetracks for neurons in our brains that when excited result in the release of chemicals (such as dopamine, a common neurotransmitter) that make us feel good. Think of how good it feels to eat when you are hungry, or to have ice cream or cookies for dessert! Consuming sugar activates our reward pathways, which explains from a neurological perspective why we like the taste of it so much. Artificial sweeteners only partially activate reward pathways, as they are sweet (which we enjoy for pleasure), but do not have the calories that we need for energy [3]. By not fully activating reward pathways, artificial sweeteners can be potentially harmful because they may, in a way, trick our brains, causing us to overeat in order to feel satisfied, or to crave even more sweetness later on. After consuming artificial sweeteners, people experience less pleasure, which should decrease appetite, yet they tend to eat more, and to choose foods that have a higher calorie count than people who consume nothing sweet, or those who consume real sugar [4]. Artificial sweeteners may make us crave real sugar even more, whereas cutting out sugars and artificial sweeteners from one's diet can lead to a decrease in sugar cravings in as little as 1 week [3].

\section{DIGESTING REAL VS. ARTIFICIAL SUGARS}

When we eat sugar, it moves from the digestive system into the bloodstream, increasing our blood sugar levels. The pancreas has the job of secreting hormones (such as insulin) into the blood to regulate our blood sugar levels. The pancreas is like a factory that turns sugars into something our bodies can use, and the factory slows down when the sugar or sweetener does not give us much energy. Artificial sweeteners do not increase blood sugar levels or insulin production, like real sugars do. This causes the pancreas to respond differently to the artificial sugars, because they give the pancreas nearly nothing to respond to. The consumption of artificial sweeteners can therefore lead to abnormal pancreas functioning and insulin levels, in addition to changes in other functions that affect our metabolism, which may put us at risk for related illnesses such as type 2 diabetes.

We all have microorganisms in our digestive systems that help break down the food we eat. Together, they are called the gut microbiota. The gut microbiota react differently to artificial sweeteners than to real sugar. 
These organisms become less able to break down real sugars the more that they are exposed to artificial sweeteners. A study conducted on mice showed that consumption of an artificial sweetener led to changes in the gut microbiota that decreased the ability of the mice to digest sugars [5]. Not being able to break down sugars is a bad thing, because this change in the microbiota can change the amount of nutrients are bodies are able to take out of the food we eat. This means that we might not get the vitamins and minerals that we need, even when we do eat the right foods.

\section{NEEDING MORE SWEETNESS AND MORE CALORIES}

Artificial sweeteners do not provide the calories or glucose that our bodies need, and they do not activate our bodies' insulin productionwhich can lead to us needing to eat more calories in order to feel full. Even though our brains and bodies process real and artificial sugars differently, sweetness of any kind increases the brain's tolerance and desire for sweetness [3]. That means that the more sweet things that you eat, the more you will have to eat in the future in order for your brain to know that something is sweet and contains the calories necessary for energy $[4,1,3]$. Craving calories and sugar because the brain has become tolerant to sweetness is a dangerous combination that can lead to over-eating, which can then lead to unwanted weight gain.

An important study was done with rats, showing that artificial sweeten-

\section{Figure 2}

Rats were provided with flavored food that was high in calories because it was sweetened with glucose (Top) or low in calories because it was sweetened with saccharin, an artificial sweetener (Bottom). Over time, the rats learned the association between the flavors and the caloric content of what they were eating. Later, when presented with the high calorie pre-feed they ended up eating less additional food than when they were given the low-calorie pre-feed, suggesting that their bodies learned to make up for the caloric deficit [3].

ers led the rats to eat more food. Adult rats were trained to associate one

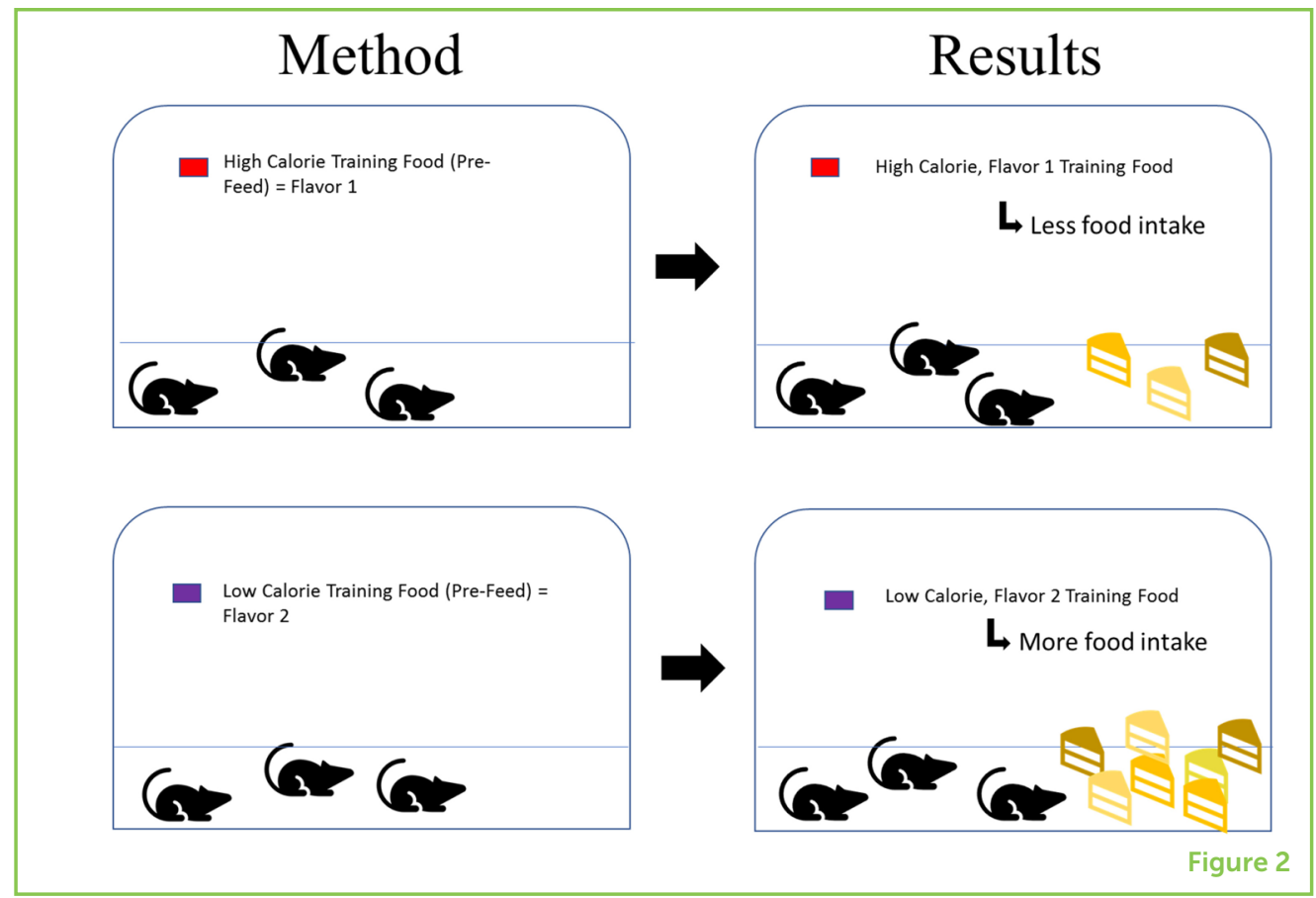


flavor with a low-calorie food (that is, one sweetened with an artificial sweetener called saccharin), and one flavor with a high-calorie food. These rats ate more food after being given a pre-feed with the same flavor as the low-calorie food (see Figure 2) [3]. This indicates a need for calories that the rats learned to make up for by consuming larger quantities of food.

In a different study, rats fed yogurt sweetened with aspartame or saccharin (artificial sugars) gained more weight than rats fed yogurt with sucrose (real sugar), even though the number of calories the mice ate was nearly the same for both groups [3]. Even though the rats were actually getting enough calories, the artificial sweeteners tricked their bodies into thinking they were not! This tendency for young rats to overeat when their bodies do not think they are getting enough calories has been shown in other animals, including humans, with artificial sweetener consumption contributing to weight gain in children.

\section{CONCLUSION}

Consuming artificial sweeteners can be enjoyable but doing so in excess (or as a replacement for sugar entirely) is dangerous, because of the differences in how our brains and bodies process these two substances, and the potential negative health consequences of over-consuming either one. Over-consumption of artificial sugars alters the body's ability to process real sugar, through changes in the gut microbiota and insulin levels. This can lead to negative health outcomes such as type 2 diabetes-while at the same time making people crave more sugar, making them want to eat more food, and potentially causing them to gain more weight. Like with so many other things in life, artificial sweeteners are not all bad, but enjoying in moderation is important!

\section{REFERENCES}

1. Swithers, S. E., and Davidson, T. L. 2008. A role for sweet taste: calorie predictive relations in energy regulation by rats. Behav. Neurosci. 122:161-73. doi: 10.1037/0735-7044.122.1.161

2. Haase, L., Cerf-Ducastel, B., and Murphy, C. 2009. Cortical activation in response to pure taste stimuli during the physiological states of hunger and satiety. Neuroimage 44:1008-21. doi: 10.1016/j.neuroimage.2008.09.044

3. Yang, Q. (2010). Gain weight by "going diet?" Artificial sweeteners and the neurobiology of sugar cravings: Neuroscience 2010. Yale J. Biol. Med. 83:101-8. https://www.ncbi.nlm.nih.gov/pmc/articles/PMC2892765/\#!po=59.3750

4. Blundell, J. E., and Hill, A. J. 1986. Paradoxical effects of an intense sweetener 
(aspartame) on appetite. Lancet 1:1092-3. https://www.ncbi.nlm.nih.gov/ pubmed/2871354

5. Suez, J., Korem, T., Zeevi, D., Zilberman-Schapira, G., Thaiss, C. A., Maza, O., et al. 2014. Artificial sweeteners induce glucose intolerance by altering the gut microbiota. Nature 514:181-6. doi: 10.1038/nature13793

SUBMITTED: 08 July 2018; ACCEPTED: 08 March 2019; PUBLISHED ONLINE: 29 March 2019.

EDITED BY: Tzipi Horowitz-Kraus, Technion Israel Institute of Technology, Israel

CITATION: Myuz H and Hout MC (2019) Trick or Treat? How Artificial Sweeteners Affect the Brain and Body. Front. Young Minds 7:51. doi: 10.3389/frym.2019.00051

CONFLICT OF INTEREST STATEMENT: The authors declare that the research was conducted in the absence of any commercial or financial relationships that could be construed as a potential conflict of interest.

COPYRIGHT @ 2019 Myuz and Hout. This is an open-access article distributed under the terms of the Creative Commons Attribution License (CC BY). The use, distribution or reproduction in other forums is permitted, provided the original author(s) and the copyright owner(s) are credited and that the original publication in this journal is cited, in accordance with accepted academic practice. No use, distribution or reproduction is permitted which does not comply with these terms.

\section{YOUNG REVIEWER}

\section{VICTORIA, AGE: 15}

I study musical theater and currently also study chemistry. My favorite types of science are astronomy and neurology.

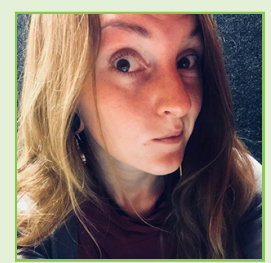

\section{AUTHORS}

\section{HUNTER MYÜZ}

Hunter Myüz is an Experimental Psychology researcher who studies religion, prejudice, statistics, hearing impairment, and haptic systems. She is working on being a better programmer, statistician, pianist, and knitter. What she enjoys most are horror movies, dogs, and the number 42.

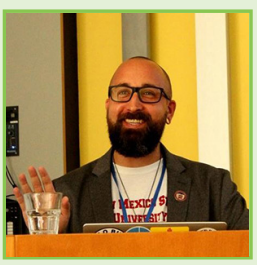

\section{MICHAEL C. HOUT}

I am an Associate Professor in the Psychology Department at New Mexico State University, and an Associate Editor at the journal Attention, Perception, \& Psychophysics. My research examines many different things, but I primarily study visual search (how people find things) and eye movements (where and why we move our eyes). In my limited spare time, I like to play with my dogs, go on motorcycle rides, hike, travel, and play hockey. *mhoutanmsu.edu 